\title{
Nitrate Removal from Groundwater Using Sodium Alginate Doped with Nano-Hydroxyapatite
}

\author{
Salah Abo-El-Enein ${ }^{1}$, Yahia Gedamy ${ }^{2,}$, Amr Ecresh ${ }^{3}$ \\ ${ }^{1}$ Chemistry Department, Faculty of Science, Ain Shams University, Cairo, Egypt \\ ${ }^{2}$ Hydrogeochemistry Department, Desert Research Center, Cairo, Egypt \\ ${ }^{3}$ North and South Sinai Company for Water and Wastewater, Sinai Peninsula, Egypt \\ Email address: \\ yahiagedamy2014@yahoo.com (Y. Gedamy) \\ *Corresponding author
}

\section{To cite this article:}

Salah Abo-El-Enein, Yahia Gedamy, Amr Ecresh. Nitrate Removal from Groundwater Using Sodium Alginate Doped with NanoHydroxyapatite. Advances in Materials. Vol. 6, No. 6, 2017, pp. 102-114. doi: 10.11648/j.am.20170606.11

Received: March 16, 2017; Accepted: April 12, 2017; Published: October 26, 2017

\begin{abstract}
In the present work, the hydroxyapatite/alginate nano-composite adsorbent was prepared by incorporating nanosized hydroxyapatite (nHAp) into alginate polymer and uses this adsorbent for removal of nitrate from groundwater. The synthesized nano-composite and pure alginate as well as the pure hydroxyapatite were characterized with Fourier Transform Infrared (FT-IR) spectroscopy to ascertain the functional groups. The adsorption characteristics of nitrate from groundwater on the HAp/Alg nano-composite were optimized under different operational parameters like contact time, $\mathrm{pH}$, adsorbent dosage, initial concentration of nitrate and temperature in batch system. Maximum equilibrium capacity reached $99 \%$ of nitrate removal by using the HAp/Alg nano-composite after 240min at $\mathrm{pH} 3$; adsorbent dosage, $2 \mathrm{~g}$; initial concentration, $100 \mathrm{mg} / \mathrm{l}$ and temperature, $20^{\circ} \mathrm{C}$. The kinetics studies revealed that the pseudo-second-order kinetic model was able to describe the dynamic behavior of the adsorption process by composite adsorbents used in this work. Also, the Langmuir isotherm model is very well fitted to the equilibrium data. The mechanism of $\mathrm{NO}_{3}{ }^{-}$ions adsorption by the nano-composite adsorbent was described. So, it is concluded that HAp/Alg nano-composite is a relatively efficient and low cost as well as the results validated the feasibility of HAp/Alg nano-composite for highly effective removal of nitrate from an aqueous solution.
\end{abstract}

Keywords: Nitrate, Hydroxyapatite/Alginate Nano-Composite, Groundwater

\section{Introduction}

Assiut governorate, one of the oldest governorates of Upper Egypt, It extends south-north between Sohag ạd ElMinya governorates from latitude $26^{\circ} 47^{\prime} \mathrm{N}$ to $27^{\circ} 37^{\prime} \mathrm{N}$ and extends west-east between New, Valley and, Red Sea governorates from longitudes $30^{\circ} 37^{\prime} \mathrm{E}$ to $31^{\circ} 34^{\prime} \mathrm{E}$ (Figure 1). The total Assiut governorate area is $25,926 \mathrm{~km}^{2}$, equivalent to about $2.6 \%$ of the total area of Egypt. The extension of the River Nile along study area is about $120 \mathrm{~km}$ while the width of the study area ranges between 10 and $20 \mathrm{~km}$ (ALDAR, 2011). Estimated population of the Assiut governorate is about 4,245,215 million (Census estimation, 2015), representing $4.8 \%$ of Egypt's total population. Groundwater quality assessment is considered as a significant topic to make sure possible safe use of this resource. As the population continues to increase, it is necessary to find additional sources of water such as groundwater. Groundwater is deemed one of the major resources for potable water in Assiut governorate especially in rural areas (ALDAR, 2011). In this study, selected samples of groundwater were collected and chemically analyzed. Analysis of these samples (Table 1) revealed that they have nitrate concentrations more than the maximum permissible limit recommended $(50 \mathrm{mg} / \mathrm{l})$ by WHO, 2011. This is due its high solubility in water and this is manifested by Hekmatzadeh et al., 2012, who state that due to its high solubility, nitrate is the most likely cause of the contamination in groundwater across the globe, and a potential threat to water resource, as well as increasing eutrophication.

Nitrate contamination in drinking water sources has been a 
major problem in many countries. The long term health hazards and increasing levels of nitrate in drinking water through natural and anthropogenic sources are challenging and warrant the need for advanced technologies for abating these contaminants (Suriyaraj and Selvakumar, 2016). The agricultural activities are the main sources of nitrate in groundwater (Ryker and Jones, 1995), as nitrogen fertilizers are frequently used in large quantities, especially for some crops such as corn and potatoes.

Table 1. Minor and trace constituent's concentrations as $\mathrm{mg} / \mathrm{l}$ in the selected groundwater samples of the study area.

\begin{tabular}{|c|c|c|c|c|c|c|c|c|}
\hline Sample No. & $\mathrm{Fe}$ & $\mathbf{P b}$ & $\mathbf{N i}$ & $\mathrm{Cu}$ & Cd & Al & Zn & $\mathrm{NO}_{3}^{-}$ \\
\hline 1 & 0.024 & 0.032 & 0.002 & 0.007 & 0.0006 & 0.02 & 0.006 & 57.75 \\
\hline 2 & 0.028 & 0.007 & 0.002 & 0.007 & 0.0006 & 0.063 & 0.004 & 65.13 \\
\hline 3 & 1.067 & 0.012 & 0.002 & 0.01 & 0.0006 & 0.166 & 0.008 & 74.18 \\
\hline
\end{tabular}

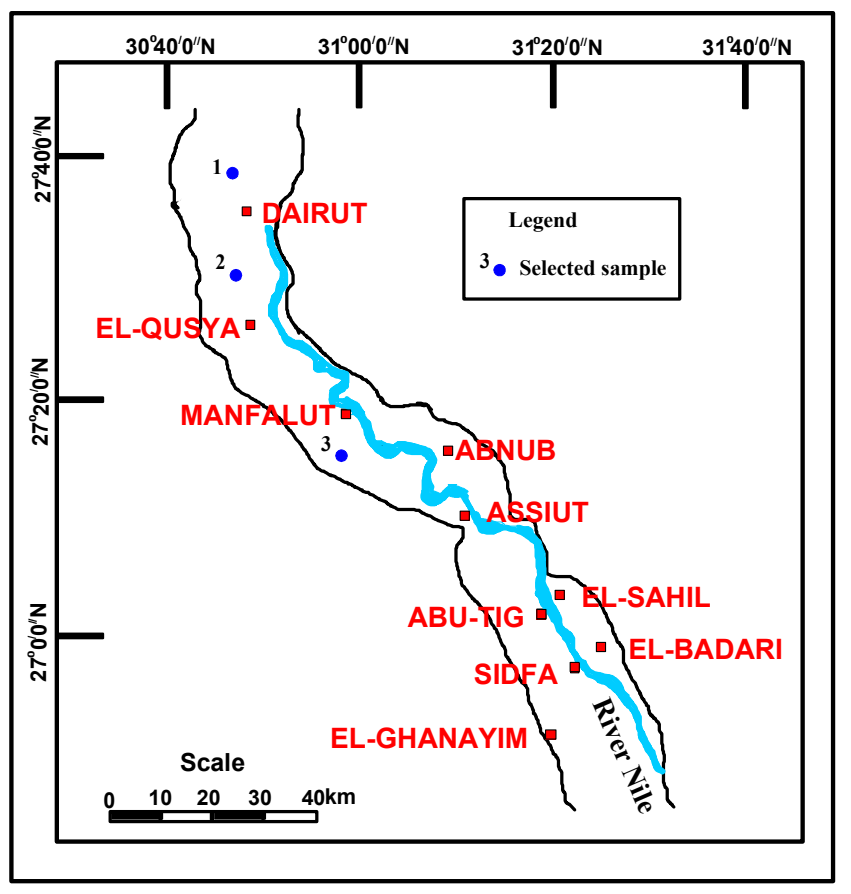

Figure 1. Location map of the study area.

Other sources of nitrogen, such as livestock operations, food processing wastes, and septic tank discharge have no substantial influence at the regional scale (Ryker and Jones, 1995). Also, from sources of nitrate and nitrite contamination are natural and industrial in origin. Industrial sources include chemical manufacturing operations and nitrate-containing cutting oils. Natural sources include atmospheric precipitation (as $\mathrm{NH}_{3}$ ) and local mineral deposits such as potassium nitrate (saltpeter), all percolate through the soil into groundwater aquifers and ultimately into water supplies.

Nitrate concentration increases in water would cause negative effects on human health: Blue baby Syndrome (Met Hemoglobin) especially in infants and the carcinogenic potential for nitrosamine (Sudipta et al., 2009). Also, recent studies indicated that increase in the amount of nitrate in drinking water would likely cause a variety of cancers in humans (Mishra and Patel, 2009). As well as large amount of nitrate in drinking water often causes a disease called methemoglobinemia and other health disorders such as hypertension (Malberg et al., 1978), increased infant mortality (Super et al., 1981), goiter (Sefner, 1995), stomach cancer (Cantor, 1997), thyroid disorder (Van Maanen et al.,
1994), cytogenetic defects (Prakasa Rao and Puttanna, 2000) and birth defects (Dorsche et al., 1984 and Kar et al., 2002). So, the removal of nitrate is essential for water contaminated with nitrate before being utilized. Because nitrate anion is stable and highly soluble with a low tendency to precipitation and absorption, so, it is difficult to remove by conventional water treatment technologies.

There are physical, chemical, and biological methods used to remove nitrate from drinking water, the chemical denitrification process using zero capacity iron, zero capacity magnesium, ion exchange, reverse osmosis, electro dialysis (Jae-HeeAhn et al., 2008). Although these techniques are effective in removing nitrate from contaminated water, they are very expensive for pilot scale operation with a limited potential application (Kapoor and Viraraghavan, 1997 \& Kesseru et al., 2002). Among other technologies used for water treatment, the adsorption process is in general low-cost, simply designed, as it is identified as an easy applicable technique (Sachin et al., 2011). Thus many researchers have focused their research work on the preparation of new efficient and cost effective adsorbents from natural or biological materials or industrial wastes. One of the promising materials, which can fulfill the desired, is natural or biogenic hydroxyapatite which is prepared from animal bones wastes (Ravikrishna et al., 2006). Many adsorbents have been used for the removal of nitrate ions, including carboxyl groups are functioning sites for binding nitrate ions, due to their large surface area, uniform pore size distribution, long-rang homogeneity of texture and modifiable surface chemistry via functionalization (Selvam et al., 2001 and Ganjali et al., 2005), they have found good use as efficient adsorbents. Alginic acid usually accumulates in seaweeds as "jelly bodies" after combining with minerals from seawater. Alginic acid is insoluble in water. The carboxyl groups within the Alginic acid forms are easily ion-exchanged, this result changes in alginate properties and functionality. Sodium alginate is a natural polysaccharide product extracted from brown seaweed that grows in cold water regions and alga. It is soluble in cold and hot water with strong agitation and can thicken and bind. It belongs to a family of linear block polyanionic copolymers composed of (1-4)-linked -D-mannuronic acid (M units) and (1-4)-linked -L-guluronic acid (G units) residues (Sutherland, 1991) as shown in Figure 2. 


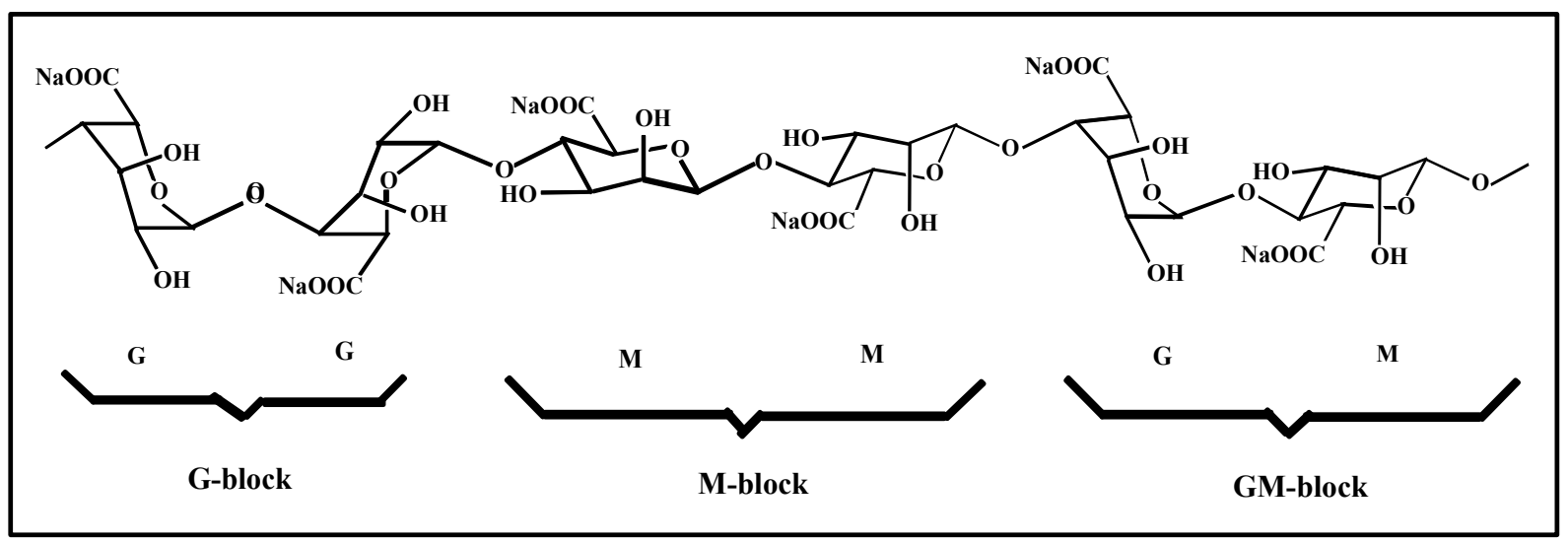

Figure 2. Chemical structure of sodium alginate.

Alginate forms stable hydrogels in the presence of certain divalent cations without the need of heat (e.g., $\mathrm{Ca}^{2+}, \mathrm{Sr}^{2+}$ and $\left.\mathrm{Ba}^{2+}\right)$ at low concentrations through the ionic interaction between the cation and the carboxyl functional group of $G$ units located on the polymer chain (Wang et al., 1993 and Honghe, 1997). According to the model presented by Grant et al., 1973, the divalent cations bridge the negatively charged $G$ units on the alginate polymer chain and form an egg-box structure. Alginate is highly hydrophilic, biocompatible, and relatively economical (Sheridan et al., 2000). Moreover, biocomposites made from both organic and inorganic components, have been introduced as immobilizing agents due to their improved mechanical, thermal, optical or chemical properties as well as their biocompatibility and biodegradability. Among these, alginate is a biopolymer with special properties such as nontoxicity, biocompatibility and biodegradability, which make it appropriate to be employed as an adsorbent (Nayak and Lahiri, 2006 \& Arica et al., 2003).

With the aim of preparing biomimetic composite, the direct nucleation of hydroxyapatite (HAp) on alginate copolymers was attempted, which is an excellent example of self-assembling process. The driving forces behind assembling of such building blocks are essentially hydrogenbonding, Van der Waals, electrostatic forces and electrontransfer interactions (Ruiz-Hitzky, 2003). In this work, briefly investigate the capability of the HAp-alginate composite bead form adsorbents for removal of nitrate from groundwater. The effect of the composition of nHApalginate composite adsorbents on nitrate removal capacity of the adsorbents was investigated. Also, governing kinetics and isotherm models were investigated.

\section{Materials and Synthesis Method}

\subsection{Materials}

All the chemicals used in this research were obtained as analytical grade and used without any further purification. The aqueous solutions were prepared using de-ionized water. Sodium alginate (with a low viscosity of $2 \mathrm{wt} \%$ solution at $25^{\circ} \mathrm{C}$ ) was purchased from Sigma-Aldrich Inc., USA, and used as received. $\mathrm{Ca}(\mathrm{OH})_{2}$ and $85 \mathrm{wt} \% \mathrm{H}_{3} \mathrm{PO}_{4}$ were used for preparation of the hydroxyapatite. $\mathrm{CaCl}_{2}$ which was used as the crosslinker for sodium alginate, were supplied from Merck Chemicals Company.

\subsection{Synthesis of nHAp/Alg Nano-Composite}

A hydroxyapatite/alginate (nHAp70/Alg30) of weight ratio nano-composite adsorbent was prepared by incorporating natural nano-sized hydroxyapatite (nHAp) into alginate polymer through in situ hybridization technique (Wang et al., 2009). This (nHAp70/Alg30) nano-composite was chosen to prepare according to (Wang et al., 2009) who stated that, it implies that the addition of alginate in excessive amount over $30 \mathrm{wt} \%$ significantly intensifies the particle agglomeration. It is not easy to achieve uniform dispersion of HA particles into the polymer matrix due to the adhesive nature of alginate. Therefore, it is suggested that the alginate content in the composites should not be higher than $30 \mathrm{wt} \%$. The molar ratio of $\mathrm{Ca} / \mathrm{P}$ in the starting mixture was set as 1.67 , equal to that of stoichiometric nHAp. An alginate gel solution $(3 \% \mathrm{w} / \mathrm{v})$ was prepared by dissolving alginate powder into distilled water. The alginate solution was added drop wise into a suspension of $\mathrm{Ca}(\mathrm{OH})_{2}(70 \mathrm{~g}, 7.37 \mathrm{wt} \%)$ under vigorous agitation. A solution of $\mathrm{H}_{3} \mathrm{PO}_{4}$ was obtained by mixing $\mathrm{H}_{3} \mathrm{PO}_{4}(4.82 \mathrm{~g}, 85 \mathrm{wt} \%)$ with $50 \mathrm{ml}$ distilled water, and then was added in drops into the $\mathrm{Alg} / \mathrm{Ca}(\mathrm{OH})_{2}$ suspension, due to nano-size of the nHAp powder $\left(\mathrm{Ca}(\mathrm{OH})_{2}+\mathrm{H}_{3} \mathrm{PO}_{4}\right)$, the particles extremely tended to agglomerate, especially when dispersed in water; therefore, dispersion process was facilitated by employing mechanical stirring and sonication (Fahimeh Googerdchianet et al., 2012). The reaction temperature was kept at $25^{\circ} \mathrm{C}$ and the mixture was stirred continuously at 700rpm for $6 \mathrm{~h}$. Then, a solution of $\mathrm{CaCl}_{2}$ $(10 \mathrm{ml}, 0.1 \mathrm{~mol} / \mathrm{l})$ was slowly added, supplying $\mathrm{Ca}^{2+}$ to crosslink alginate. After half an hour of crosslinkage, the gellike mixture was centrifuged and water-washed alternately for three cycles to harvest the precipitates, i.e., the washing is for removing the excess $\mathrm{Ca}^{2+}$ and other impurities on the surface of the beds (Zhang et al., 2010). The precipitates were vacuum-dried at $50^{\circ} \mathrm{C}$ for $48 \mathrm{~h}$ and subsequently ground into fine powders using an agate mortar. Meanwhile, pure nHAp without alginate involved was prepared as a control 
sample according to the following reaction;

$$
10 \mathrm{Ca}(\mathrm{OH})_{2}+6 \mathrm{H}_{3} \mathrm{PO}_{4} \rightarrow \mathrm{Ca}_{10}\left(\mathrm{PO}_{4}\right)_{6}(\mathrm{OH})_{2}+18 \mathrm{H}_{2} \mathrm{O}
$$

Noteworthy to mention that, the suggested mechanism for the reaction that occurred between sodium alginate and hydroxyapatite with addition of calcium chloride can be expressed as in Figure (3).

\subsection{Measurements}

Pure sodium alginate (SA) and pure nano-sized hydroxyapatite (nHAp) as well as hydroxyapatite/alginate bio-composite nanoparticles (nHAp/ALg) were subjected to Fourier Transform Infrared analysis (FT-IR, Perkin Elmer, model No. L1600300, UK) with a spectrometer. Infrared spectroscopy IR was carried out after dispersion of the sample in anhydrous $\mathrm{KBr}$ pellets. At first the powdered sample was carefully mixed with $\mathrm{KBr}$ (infrared grade) by mixing a ratio $1: 9$ and compressed to form a disk and palletized under vacuum. The IR spectra of the samples were recorded in transmittance mode over a wave No. of 400 to $4000 \mathrm{~cm}-1$ at ambient temperature $\left(25^{\circ} \mathrm{C}\right)$. The pellet was prepared by taking the mixture in a $\mathrm{KBr}$ Die and a pressure of 5 Ton was applied using a pellet holder. The instrument was switched on and background scan was obtained without placing the pellet. Then the pellet was placed and 16 scan was obtained. Then date plotted using standard software provided with the instrument on the length of the bond

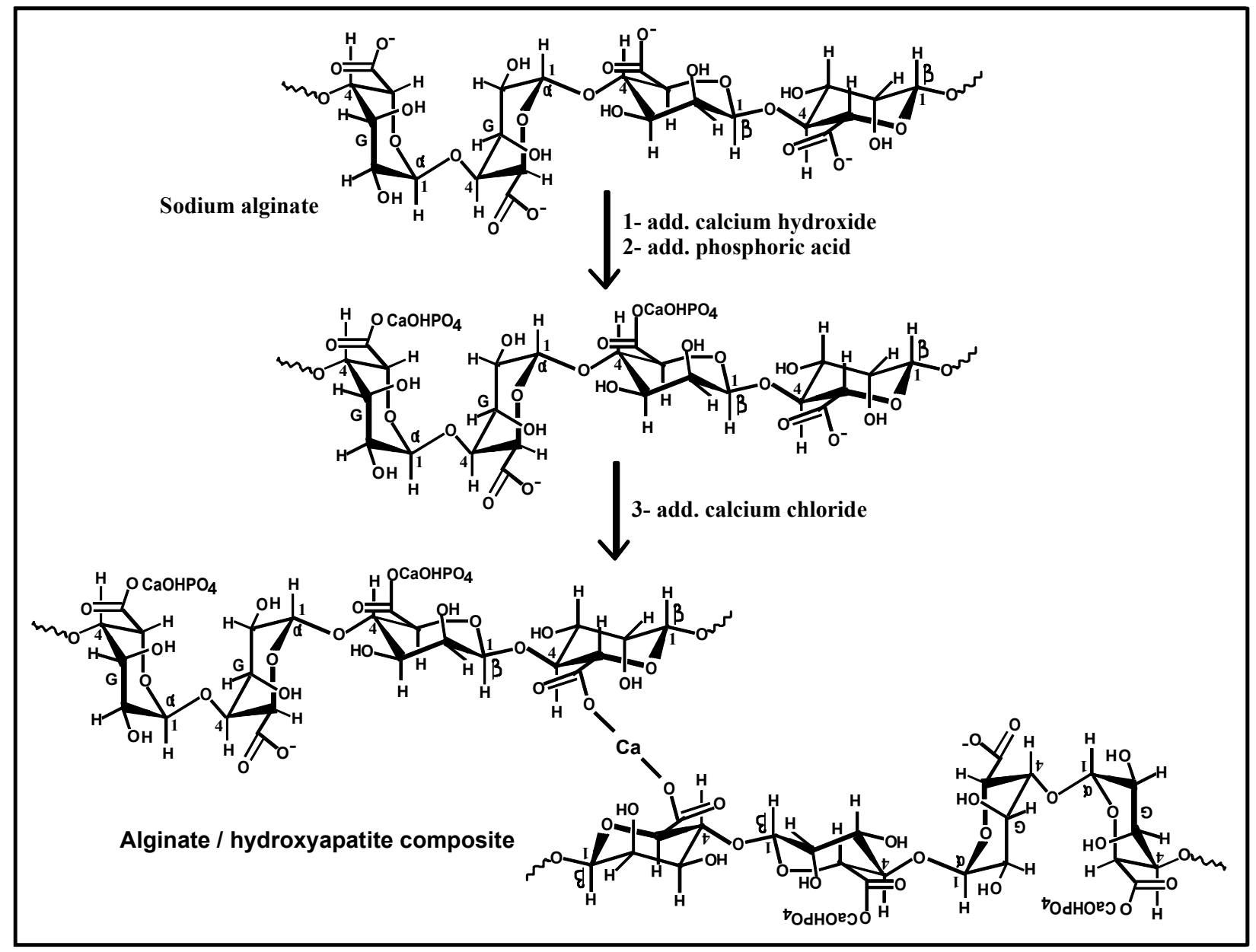

Figure 3. The suggested reaction mechanism for synthesis of hydroxyapatite/alginate nano-composite.

\section{Results and Discussion}

\subsection{Characterization of Nano-Powders and Nano-Composites}

Infrared spectroscopy is a useful tool to identify the presence of certain functional groups in a molecule because each specific chemical bond often has unique energy absorption band. Chemical bonds have specific frequencies when they vibrate. These resonant frequencies are dependent the mass of the atoms at either end of it. Thus, the frequency of the vibrations can be associated with a particular bond type.

The Fourier Transforms Infrared (FT-IR) spectra of the pure sodium alginate and pure hydroxyapatite as well as hydroxyapatite/alginate nano-composite were recorded in Figures 4, 5 and 6.

Spectrum of sodium alginate (Figure 4) shows a broad peak at $3430 \mathrm{~cm}^{-1}$ representing the stretching vibrations of O$\mathrm{H}$ bonds of alginate. Stretching vibrations of aliphatic $\mathrm{C}-\mathrm{H}$ 
were observed at $2950-2850 \mathrm{~cm}^{-1}$. The peaks at 1690 and $1480 \mathrm{~cm}^{-1}$ have been assigned to the asymmetric and symmetric stretching vibrations of carboxyl groups, respectively. These bands are very significant and can be used for characterization of alginate structure from its derivatives and ingredients. The bands at 1150 and $950 \mathrm{~cm}^{-1}$ were attributed to stretching vibrations of the $\mathrm{C}-\mathrm{O}$ bond of the ring. The observed beak at $850 \mathrm{~cm}^{-1}$ is represented to the bending mode of $\mathrm{O}-\mathrm{H}$ group.

In spectra of pure hydroxyapatite (Figure 5), the observed band at $3449 \mathrm{~cm}^{-1}$ is attributed to the stretching vibration of the hydrogen bond $\mathrm{O}-\mathrm{H}$ ions. The peaks at 1636 and $1399 \mathrm{~cm}^{-}$ ${ }^{1}$ representing to the carbonate ions, indicating the presence of carbonate apatite. This might originate from adsorption of carbon dioxide from the atmosphere (Komath and Varma, 2003). The following peaks will be observed, where all pertaining to the phosphate group; the asymmetric stretching mode at $1020 \mathrm{~cm}^{-1}$, the symmetric stretching mode at $980 \mathrm{~cm}^{-}$ 1 , while there are three bands were identified at 873,650 and $567 \mathrm{~cm}^{-1}$ and representing the bending mode of phosphorousoxygen bonded of $\mathrm{PO}_{4}{ }^{3-}$ ions.

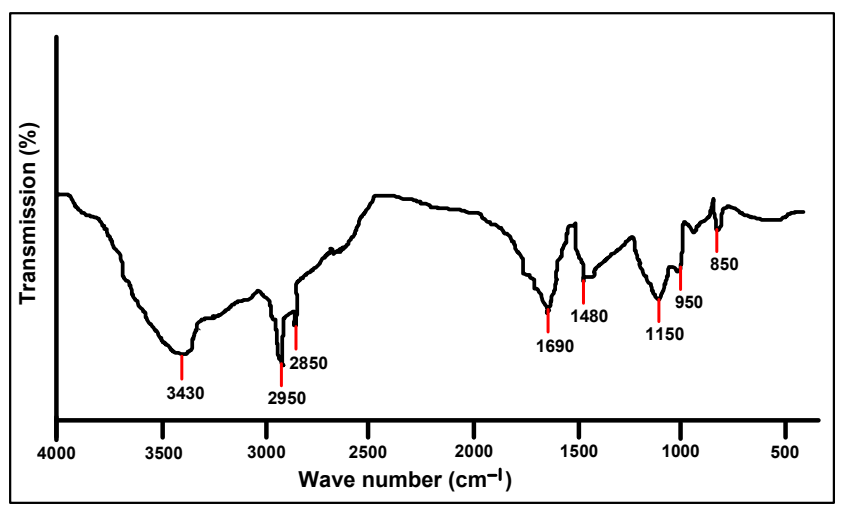

Figure 4. FT-IR spectra of pure alginate.

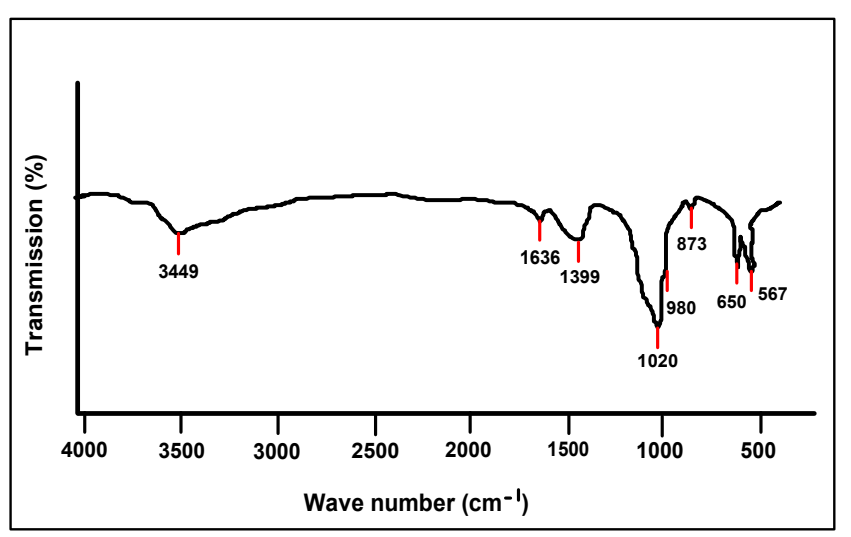

Figure 5. FT-IR spectra of pure hydroxyapatite.

In spectra of hydroxyapatite/alginate nano-composite (Figure 6), the observed band at $3450 \mathrm{~cm}^{-1}$ is attributed to the stretching vibrations of the $\mathrm{O}-\mathrm{H}$ bonds. Noteworthy to mention that, adsorption of stretching vibrations of $\mathrm{O}-\mathrm{H}$ bonds in alginate/hydroxyapatite nano-composite appeared narrower than sodium alginate. This difference may be arise from the participation of hydroxyl and carboxylate groups of alginate to the calcium ion in order to form chelating structure and consequent decrease in hydrogen bonding between hydroxyl functional groups which affords narrower band in alginate/hydroxyapatite nano-composite. On the other hand, a notable peak shift from 1636 to $1600 \mathrm{~cm}^{-1}$ in the Fourier Transform Infrared spectra of the nano-composite was observed towards the lower wave number side when compared with pure hydroxyapatite. It reveals a strong interaction between the positively charged of calcium $\left(\mathrm{Ca}^{2+}\right)$ and the negatively charged of carboxyl group $\left(\mathrm{COO}^{-}\right)$in sodium alginate (Kikuchi et al., 2001 and Teng et al., 2006). The band at $1650 \mathrm{~cm}^{-1}$ corresponding to the stretching vibration of $\mathrm{C}=\mathrm{O}$ groups of carboxylic appear to be shifted. This is probably due to the interaction with the calcium atoms of the HAp with the oxygen sites of alginate. The band at $1050 \mathrm{~cm}^{-1}$ is corresponding to phosphate stretching $\mathrm{PO}_{4}{ }^{3-}$. The band at $880 \mathrm{~cm}^{-1}$ is corresponding to the bending mode of $\mathrm{O}-\mathrm{H}$ group. The bands at 600 and $570 \mathrm{~cm}^{-1}$ were corresponded to phosphate-bending vibrations. The presence of the peaks regarding to the hydroxyl and phosphate groups that corresponded to the alginate and hydroxyapatite, is a good indication for the formation of the alginate/hydroxyapatite nano-composite.

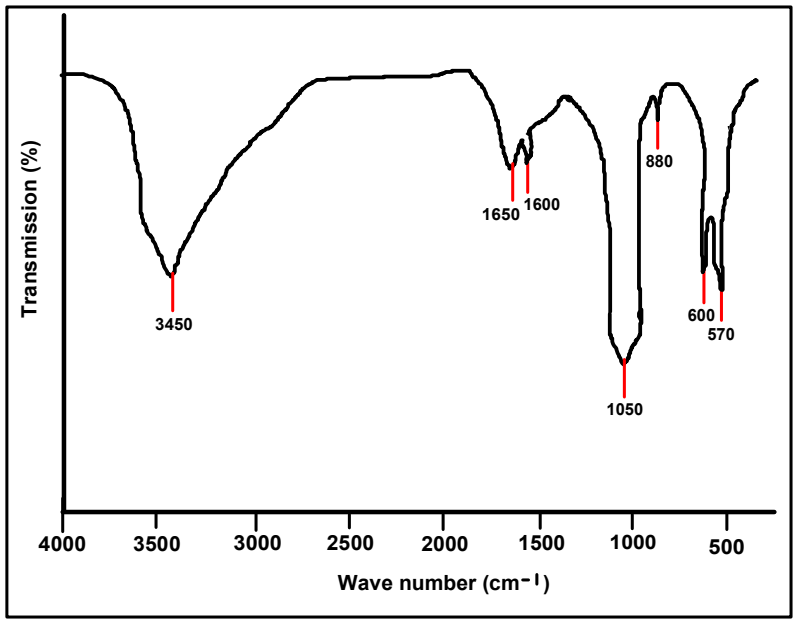

Figure 6. FT-IR spectra of hydroxyapatite / alginate nano-composite.

\subsection{Adsorption Study}

The sorption performance of the nitrate ion on the HAp/Alg nano-composite was investigated by the batch method. All the experiments were carried out at ambient temperature $20^{\circ} \mathrm{C}$ and all the samples were maintained at the same temperature to avoid interference due to the difference in temperature. All adsorption experiments were carried out in $250 \mathrm{ml}$ glass conical flasks provided with stopper (stoppers were provided to avoid the change of concentration due to evaporation) and vibrated at a constant speed of 240rpm in a shaker and each adsorbent was separated by centrifuge at speed of 3000rpm and the nitrate concentration of each filtrate solution was immediately measured using UV/vis spectrophotometer (Perkin Elmer - Lambda 35) at 430nm wavelength. The effect of contact time $(5,50,100,150,200$, 250 and $300 \mathrm{~min}), \mathrm{pH}(2-8)$, adsorbent dosage (1-6g/l), initial 
nitrate concentration $(100,150,200,250$ and $300 \mathrm{mg} / \mathrm{l})$ and temperature $\left(20,40\right.$ and $\left.60^{\circ} \mathrm{C}\right)$ on the nitrate adsorption was studied. Each experiment was repeated three times and the given results were the average values.

The difference between the initial and final concentrations of nitrate in aqueous phase was calculated, the amount of adsorbed nitrate at equilibrium $\left(\mathrm{q}_{\mathrm{e}}, \mathrm{mg} / \mathrm{g}\right)$ was calculated by the following equation;

$$
\mathrm{q}_{e}=\frac{\left(\mathrm{C}_{i}-\mathrm{C}_{t}\right) \mathrm{V}}{\mathrm{m}} \times 1000
$$

Where;

$\mathrm{q}_{\mathrm{e}}$ : quantity of nitrate adsorbed per gram of adsorbent $(\mathrm{mg} / \mathrm{g})$.

$\mathrm{C}_{\mathrm{i}}$ : the initial nitrate concentration $(\mathrm{mg} / 1)$.

$\mathrm{C}_{\mathrm{t}}$ : the nitrate concentration at time $\mathrm{t}(\mathrm{mg} / \mathrm{l})$.

$\mathrm{V}$ : the volume $(\mathrm{L})$ of aqueous solution containing nitrate.

$\mathrm{m}$ : the mass of HAp/Alg nano-composite adsorbent (g).

\subsubsection{Effect of Contact Time}

The equilibrium time required for the adsorption of nitrate using HAp/Alg nano-composite was studied at different time intervals $(5,50,100,150,200,250$ and $300 \mathrm{~min})$. About $2 \mathrm{~g}$ of the adsorbent was mixed with $50 \mathrm{ml}$ of the stock nitrate solution have an initial nitrate concentration of $100 \mathrm{mg} / \mathrm{l}$. The contents were shaken thoroughly using a mechanical shaker at 240rpm and after the contact time, the contents were filtered and analyzed for nitrate. The result as shown in Figure (7) shows that the adsorption capacity $\left(\mathrm{q}_{\mathrm{e}}\right)$ of the sorbent increases with increasing contact time and attains maximum removal at $240 \mathrm{~min}$ incubation period, i.e., the nutrients adsorption increased rapidly during the first $30 \mathrm{~min}$ and remained up to $240 \mathrm{~min}$. Such rapid bio-sorption process has been correlated with the characteristics of the biomass, and its other parameters interact with the aqueous solutions (Ingleton and Simmons, 1996). In other words, the change in the rate of removal might be due to the fact that initially all adsorbent sites contained replaceable hydroxide and carboxylic ions and the solute concentration gradient was also high. Later, the nitrate uptake rate by adsorbent was decreased significantly, due to the decrease in number of replaceable hydroxide and carboxylic ions in adsorption sites as well as decrease in nitrate concentration. Decreased removal rate, particularly, towards the end of experiments, indicates the possible monolayer formation of nitrate ion on the outer surface (Mahamudur Islam et al., 2010). Also, the results showed that the $240 \mathrm{~min}$ duration was found suitable for maximum adsorption of nitrate from the groundwater using HAp/Alg nano-composite. Noteworthy to mentioning that, from Figure (7), it is noticed that the high adsorption capacity $\left(\mathrm{q}_{\mathrm{e}}\right)$ for $\mathrm{HAp} / \mathrm{Alg}$ nano-composite was found $22.53 \mathrm{mg} / \mathrm{g}$ at $240 \mathrm{~min}$ contact time.

\subsubsection{Effect of $\mathrm{pH}$}

The effect of the solution $\mathrm{pH}$ on the adsorption behavior was determined at a constant temperature of $20^{\circ} \mathrm{C}$ for $4 \mathrm{~h}$. In batch experiment, $2 \mathrm{~g}$ of the adsorbent was equilibrated with
$50 \mathrm{ml}$ of the solution containing $100 \mathrm{mg} / \mathrm{l}$ of nitrate concentration at various $\mathrm{pH}$ values ( $\mathrm{pH}$ range of $2-8$ ).

As the $\mathrm{pH}$ increases, the removal of nitrate increases. Figure (8) shows the change in the adsorptions capacity due to the change of $\mathrm{pH}$. It is noticed that the removal of nitrate was greater by HAp/Alg nano-composite adsorbent at $\mathrm{pH} 3$ and the maximum sorption capacity was achieved $22.48 \mathrm{mg} / \mathrm{g}$.

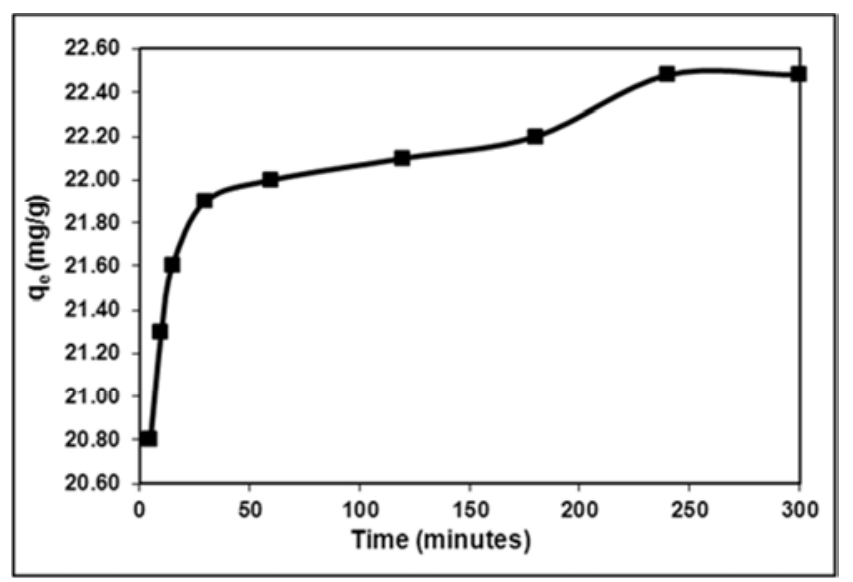

Figure 7. Effect of contact time on nitrate adsorption by HAp/Alg nanocomposites at given conditions: $\mathrm{pH}, 3$; dosage, $2 \mathrm{~g}$ and $\mathrm{Ci}, 100 \mathrm{mg} / \mathrm{l}$ at $20^{\circ} \mathrm{C}$.

It is well known that $\mathrm{pH}$ of the medium, is one of the most important factors that influence the adsorption process. This is due to the competitive effect of the $\mathrm{H}^{+}$and also due to the fact that the $\mathrm{pH}$ affects the ionization of the functional groups on the surface of the sorbent material (Wahab et al., 2010). Seven different $\mathrm{pH}$ tests were carried out and the results are shown in Figure (8). The initial $\mathrm{pH}$ values of each solution were adjusted using $0.1 \mathrm{M}$ of $\mathrm{NaOH}$ and $\mathrm{HCl}$. The sorption capacity of nitrate increases by $\mathrm{HAp} / \mathrm{Alg}$ nano-composite with increasing the $\mathrm{pH}$ from 2 to 8 . It is evident from the results that are shown in Figure (8). There are increases in sorption capacity with increasing $\mathrm{pH}$ from 2 to 3 but for further increase in $\mathrm{pH}$ beyond 3, there wasn't nearly any increase in the removal. It may due to the fact that HAp/Alg nano-composite is not stable under acidic condition and hence exhibited poor removal efficiency and the removal stood almost constant for $\mathrm{pH} 3-8$. According to the results, the $\mathrm{pH}$ does not affect the nitrate removed for $\mathrm{pH}$ above 3 . However the $\mathrm{pH}$ below 3 has a significant effect. Therefore care must be taken with acidic solutions.

Experiments performed with lower $\mathrm{pH}$ indicated that as $\mathrm{pH}$ drops due to $\mathrm{HCl}$ interaction added to the solution beside nitrate ions have negative charge, so decreases adsorption level was found. Decreasing $\mathrm{pH}$ less than 3 revealed that adsorption level rises due to electrostatic interactions between positive surface charge and anions, as it will decline for higher $\mathrm{pH}$. However, the difference of adsorption level was low when the $\mathrm{pH}$ varied between $2-8$ solutions, and given the nitrate concentration level of primary sample and the level of essential removal in order to reach a standard level. It is important to reach a desired result with the same natural $\mathrm{pH}$ of water by consuming little energy.

In other words, the removal of nitrate increases quickly at 
pH 2-3 and then remains constant at $\mathrm{pH} 3-8$. This behavior can be attributed to the synergic effect of functional groups in $\mathrm{HAp} / \mathrm{Alg}$ nano-composite. Under these conditions, uptake conditions for nitrate are improved with protonation of $\mathrm{COOH},-\mathrm{OH}$ and $-\mathrm{PO}_{4}{ }^{3-}$ groups in $\mathrm{HAp} / \mathrm{Alg}$ nano-composite at $\mathrm{pH}$ 2-3. On the other hand, the $-\mathrm{COOH},-\mathrm{OH}$ and $-\mathrm{PO}_{4}{ }^{3-}$ groups in $\mathrm{HAp} / \mathrm{Alg}$ nano-composite have proton exchange ability with nitrate ions at higher $\mathrm{pHs}$ (above 3 ), which can be represented as the following reactions;

1) At pH 2-3;

$$
\underset{\mid}{\mathrm{HOOC}-\mathrm{HAp} / \mathrm{Alg}-\mathrm{OH}}+\mathrm{H}^{+} \leftrightharpoons{ }_{\mathrm{PO}_{4}{ }^{3-}}^{{ }^{3}} \mathrm{H}_{2} \mathrm{OOC}-\mathrm{HAp} / \mathrm{Alg}-\mathrm{OH}_{2}{ }^{+}
$$

2) At pH 3-8;

$$
\mathrm{HOOC}-\mathrm{HAp} / \mathrm{Alg}-\mathrm{OH}-\mathrm{H}^{+} \leftrightharpoons{ }^{-} \mathrm{OOC}-\mathrm{HAp} / \mathrm{Alg}-\mathrm{O}^{-}
$$

Where, both the protonated carboxyl, hydroxyl and phosphate groups on HAp/Alg nano-composite can function as the binding sites for capturing $\mathrm{NO}_{3}{ }^{-}$ions at $\mathrm{pH} 2-3$. On the other hand, $\mathrm{NO}_{3}^{-}$ions were retained mainly by electrostatic interaction with the deprotonated carboxyl and hydroxyl groups at pH 3-8. This is manifested by Elmoubarki et al., 2015 who stated that the variation of adsorption with $\mathrm{pH}$ can be explained by the electrostatic interaction between the adsorbent and adsorbate. With increase of $\mathrm{pH}$ values, the surfaces gradually decrease in the extent of positive charging and become negative at $\mathrm{pH}$ more than 3 . Thus, the high adsorption capacity at low $\mathrm{pH}$ is mainly due to the strong electrostatic interaction between the positively charged sites of adsorbent (presence of $\mathrm{H}^{+}$) and the anions. However, lower sorption of the nitrates ions at alkaline $\mathrm{pH}$ could be attributed to the abundance of $\mathrm{OH}^{-}$ions which will compete with the pollutant for the same sorption sites (Elmoubarki et al., 2015).

Noteworthy to mention that, Yuh-Shan Ho. (2005) stated that the high velocity of adsorption level at $\mathrm{pH} 2-3$ is due to the capacities available for adsorption of both adsorbents in early minutes. Filling these capacities, the rate of adsorption is reduced.

\subsubsection{Effect of HAp/Alg Nano-Composite Dosage}

Studying the effect of adsorbent mass (dosage) on nitrate adsorption onto HAp/Alg nano-composite, experiments were performed with varying amounts of adsorbent, ranging from 1 to $6 \mathrm{~g}$. The effect of variation of adsorbent dose on the adsorption capacity $\left(\mathrm{q}_{\mathrm{e}}\right)$ of nitrate from groundwater with $\mathrm{HAp} / \mathrm{Alg}$ nano-composite is graphically shown in Figure (9). It is evident from the figure that the removal of nitrate increases from $1-2 \mathrm{~g}$ and remains constant after the dosage 2 to $6 \mathrm{~g}$. This revealed that the adsorption capacity $\left(\mathrm{q}_{\mathrm{e}}\right)$ of the $\mathrm{HAp} / \mathrm{Alg}$ nano-composite increases with increasing adsorbent dose $(1-2 \mathrm{~g})$ up to a particular region and then reaches an equilibrium level (no significance change) at higher doses (2-6g). This may be due to the overlapping of active sites at the higher dosage. So, there was not any appreciable increase in the effective surface area due to the conglomeration of exchanger particles (Tahir, 2005). In other words, this trend could be due to the formation of adsorbent aggregates at higher adsorbent concentrations, which in turn could reduce the effective surface area available for the adsorption (Soumya et al., 2015). So, $2 \mathrm{~g}$ was considered as an optimum dose and was used for further study.

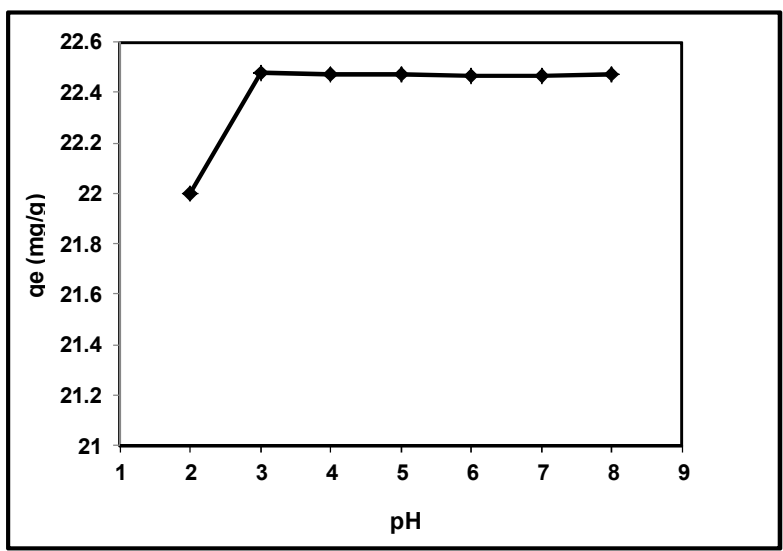

Figure 8. Effect of $p H$ on nitrate adsorption by HAp/Alg nano-composite at given conditions: contact time, 240min; dosage, $2 \mathrm{~g}$ and $\mathrm{Ci}, 100 \mathrm{mg} / \mathrm{l}$ at $20^{\circ} \mathrm{C}$.

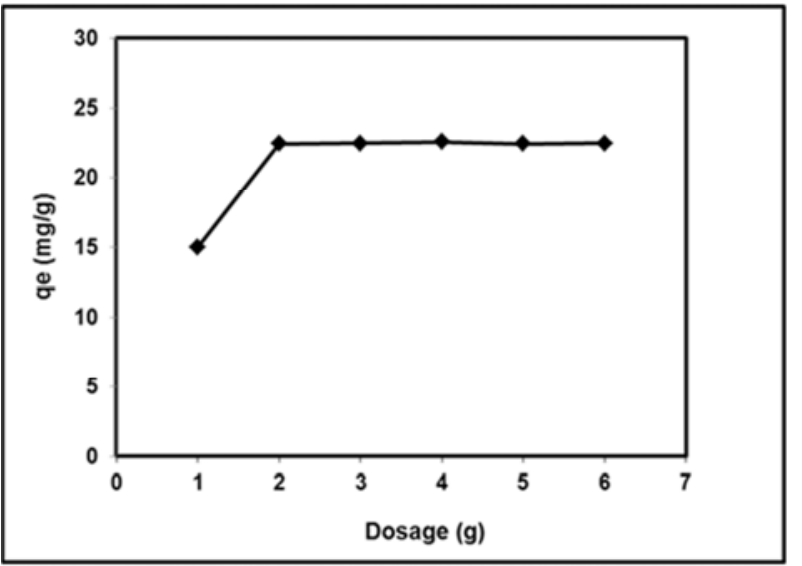

Figure 9. Effect of HAp/Alg nano-composite dosage on nitrate adsorption at given conditions: contact time, 240min; $\mathrm{pH}, 3$ and $\mathrm{Ci}, 100 \mathrm{mg} / \mathrm{l}$ at $20^{\circ} \mathrm{C}$.

\subsubsection{Effect of Initial Nitrate Concentration}

The effect of the initial nitrate concentration on the removal of nitrate has been examined on the HAp/Alg nanocomposite (Figure 10). The initial concentration of nitrate solution was varied from $100 \mathrm{mg} / 1$ to $300 \mathrm{mg} / 1$ with optimum adsorbent dose $(2 \mathrm{~g})$. It is evident from the graph that the adsorption capacity $\left(\mathrm{q}_{\mathrm{e}}\right)$ of nitrate decreased from 22.5 to $21.7 \mathrm{mg} / \mathrm{g}$ of the initial nitrate concentration of $100 \mathrm{mg} / \mathrm{l}$ to $300 \mathrm{mg} / 1$, i.e., the amount of nitrate adsorbed decreases with increasing the nitrate concentration. It is due to the limitation of adsorption sites on the nano-composite surface (Moussavi and Khosravi, 2011) and (Vimonses et al., 2009). Also, this can be explained as follows; with increasing the initial nitrate concentration, the amount of adsorbate species in the solution increases, but the amount of adsorbent remains constant and hence the adsorption capacity $\left(\mathrm{q}_{\mathrm{e}}\right)$ decreases with increase in the initial nitrate concentration, i.e., the higher uptake of nitrate at low concentration may be attributed to the availablity of more active sites on the lesser number of adsorbate species (Islam and Patel, 2011). In other words, the 
amount of nitrate adsorbed decreases with the increase in the initial nitrate concentration which attributed to the saturation of binding sites on the biomass surface leading to increase number of unabsorbed ions from the aqueous solution, because of the lack of binding sites on the biomass at higher concentrations than 100mg/l (Akçelik et al., 2008).

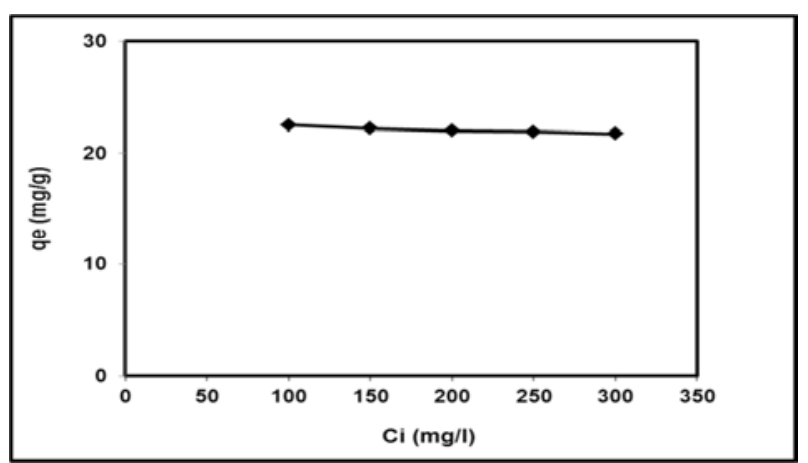

Figure 10. Effect of initial nitrate concentration on adsorption by HAp/Alg nano-composites at given conditions: contact time, 240min; $\mathrm{pH}, 3$ and dosage, $2 \mathrm{~g}$ at $20^{\circ} \mathrm{C}$.

\subsubsection{Temperature Effect}

The adsorption studies were carried out at three different temperatures $\left(20,40\right.$, and $\left.60^{\circ} \mathrm{C}\right)$ and the results of these experiments are shown in Figure (11). The increase of removal of $\mathrm{NO}_{3}^{-}$with temperature indicates that $\mathrm{NO}_{3}^{-}$is favorably adsorbed by Hap/Alg nano-composite adsorbent at higher temperatures, which shows that the adsorption process may be an endothermic one. This may be due to the increase in the mobility of $\mathrm{NO}_{3}^{-}$with increasing temperature. An increasing number of molecules may also acquire sufficient energy to undergo interaction with active sites at the surface of Hap/Alg nano-composite adsorbent. Furthermore, increasing temperature may produce a swelling effect within the internal structure of the nano-sized Hap/Alg nano-composite adsorbent enabling large metal ions to penetrate further (Do gan and Alkan, 2003).

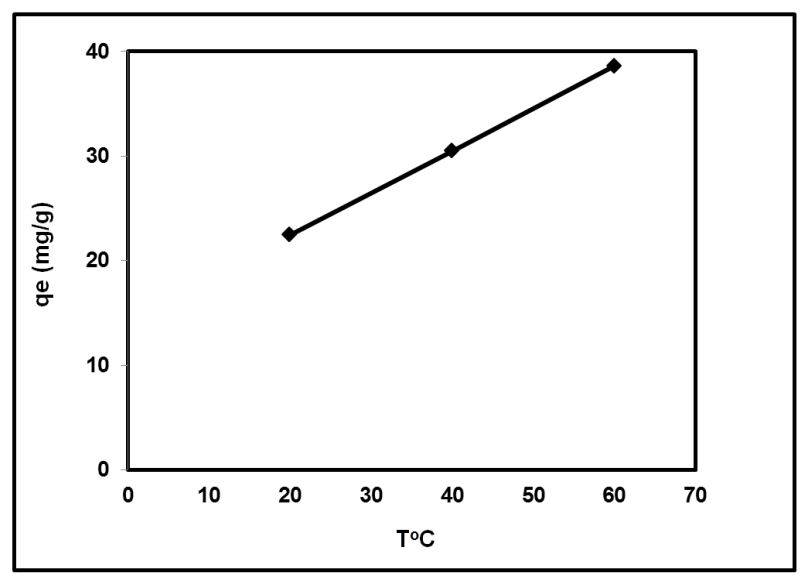

Figure 11. Effect of temperature on nitrate adsorption by HAp/Alg nanocomposites at given conditions: contact time, 240min; $p H, 3$; dosage, $2 g$ and $\mathrm{Ci}, 100 \mathrm{mg} / \mathrm{l}$.

\subsection{Adsorption Kinetics}

It is considered one of the most important characteristics when dealing with the efficiency of adsorption. In order to investigate the controlling mechanism of adsorption processes, such as mass transfer and chemical reaction, firstorder and pseudo-second-order as well as intra-particle diffusion equations are applied to model the kinetics of nitrate adsorption onto HAp/Alg nano-composite adsorbent.

In a typical kinetic test, $2 \mathrm{~g}$ of the adsorbent was added to $50 \mathrm{ml}$ of $100 \mathrm{mg} / 1$ nitrate ion solution at $\mathrm{pH} 3$. The suspension was agitated for different periods of time (from $5 \mathrm{~min}$ to 300min) using a shaker.

The plots of $\mathrm{q}_{\mathrm{t}}$ versus $\mathrm{t}$ for the HAp/Alg nano-composite adsorbent system is found to be exponential indicating the first order nature of the adsorption process (Figure 12). In order to find out whether the adsorption process followed first order kinetics the following generalized first-order kinetic equation proposed by (Annadurai and Krishnan, 1996) was employed;

$$
1 / \mathrm{q}_{\mathrm{t}}=\left(\mathrm{k}_{1} / \mathrm{q}_{1}\right)(1 / \mathrm{t})+1 / \mathrm{q}_{1}
$$

Where $q_{t}$ and $q_{1}$ are the amounts of nitrate ions adsorbed per unit mass of adsorbent in $(\mathrm{mg} / \mathrm{g})$ at various time $\mathrm{t}$, and at equilibrium stage, respectively. Also, $\mathrm{k}_{1}$ is the first order rate constant for the adsorption process in $\left(\mathrm{min}^{-1}\right)$. Linear correlations of $1 / q_{t}$ versus $1 / t$ were made and the rate constant $\mathrm{k}_{1}$ and $\mathrm{q}_{1}$ can be determined from the intercept and slope of the line, respectively, as given in the table (2).

The pseudo second-order adsorption kinetic rate equation is expressed as;

$$
\mathrm{dq}_{\mathrm{t}} / \mathrm{d}_{\mathrm{t}}=\mathrm{k}_{2}\left(\mathrm{q}_{2}-\mathrm{q}_{\mathrm{t}}\right)^{2}
$$

Where: $\mathrm{k}_{2}$ is the rate constant of pseudo second-order adsorption and it is expressed in $\left(\mathrm{g} \mathrm{mg}^{-1} \mathrm{~min}^{-1}\right)$. For the boundary conditions $\mathrm{t}=0$ to $\mathrm{t}=\mathrm{t}$ and $\mathrm{q}_{\mathrm{t}}=0$ to $\mathrm{q}_{\mathrm{t}}=\mathrm{q}_{\mathrm{t}}$ the integrated form of Equation (2) becomes;

$$
1 /\left(\mathrm{q}_{2}-\mathrm{q}_{\mathrm{t}}\right)=1 / \mathrm{q}_{2}+\mathrm{k}_{2} \mathrm{t}
$$

This is the integrated rate law for a pseudo second-order reaction. Equation (3) can be rearranged to obtain Eq. (4), which has a linear form:

$$
\mathrm{t} / \mathrm{q}_{\mathrm{t}}=\left(1 / \mathrm{k}_{2} \mathrm{q}_{2}^{2}\right)+\left(1 / \mathrm{q}_{2}\right) \mathrm{t}
$$

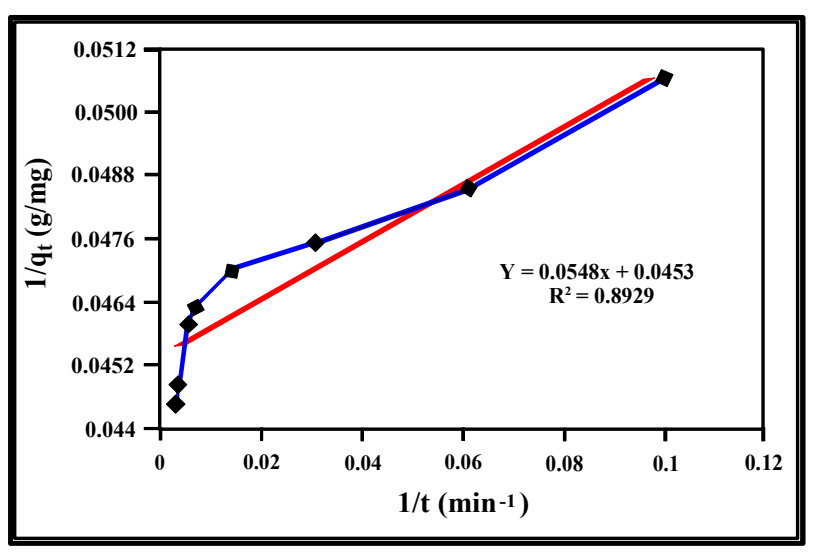

Figure 12. The first-order kinetic model of nitrate adsorption on HAp/Alg nano-composite at given conditions: contact time, 240min; $\mathrm{pH}, 3$; dosage, $2 \mathrm{~g}$ and $\mathrm{Ci}, 100$ at $20^{\circ} \mathrm{C}$. 
Where $\mathrm{q}_{\mathrm{t}}$ and $\mathrm{q}_{2}$ are the amounts of nitrate ions removed per unit mass of adsorbent in $(\mathrm{mg} / \mathrm{g})$ at an arbitrary contact time $\mathrm{t}$ and at equilibrium stage, respectively. Also, the initial adsorption rate is represented by $\left(\mathrm{k}_{2} \mathrm{q}_{2}{ }^{2}\right)$ and it is expressed in $\left(\mathrm{mg} \mathrm{g}^{-1} \mathrm{~min}^{-1}\right)$. Once $\mathrm{t} / \mathrm{q}_{\mathrm{t}}$ is plotted versus $\mathrm{t}$, if a linear graph is obtained, the rate constant and $\mathrm{q}_{2}$ can be determined from the intercept and slope of the line, respectively (Ho and McKay, 1999). The result of linear curve fitting to the dynamic data for HAp/Alg nano-composite adsorbent is shown in Figure (13). In addition, the kinetic model parameters as well as regression coefficient $\left(\mathrm{R}^{2}\right)$ for the adsorbent is reported in Table (2). The $\mathrm{R}^{2}$ values very close to one reveal that pseudo second-order kinetic model can describe successfully the dynamic behavior of adsorption process for the adsorbent prepared and used in this work.

In order to test the existence of intra-particle diffusion in the adsorption process, the amount of nitrate sorbed per unit mass of adsorbents, $q$ at any time $t$, was plotted as a function of square root of time $\left(\mathrm{t}^{1 / 2}\right)$. The rate constant for intraparticle diffusion was obtained using Weber-Morris equation given as follows (Yadav et al., 2006);

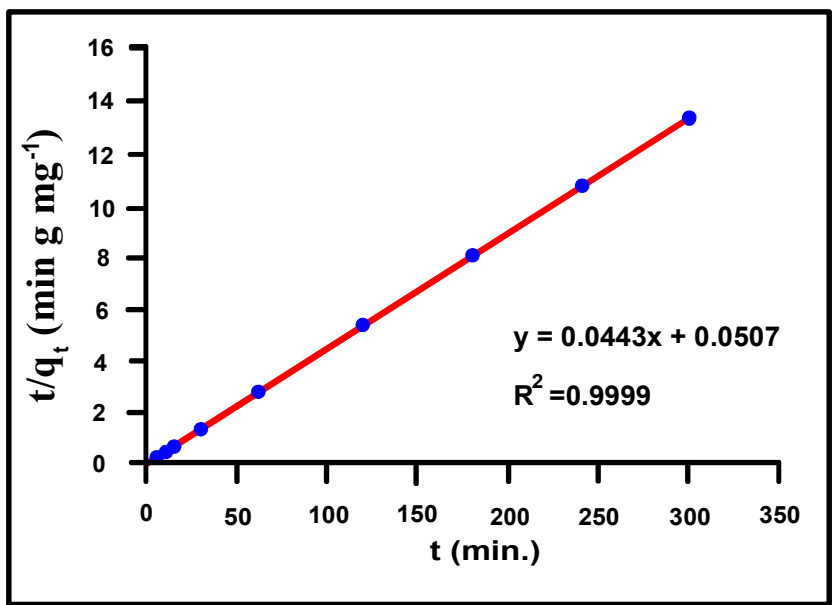

Figure 13. The pseudo second-order kinetic model of nitrate adsorption on HAp/Alg nano-composite at given conditions: contact time, 240min; $\mathrm{pH}, 3$; dosage, $2 \mathrm{~g}$ and $\mathrm{Ci}, 100$ at $20^{\circ} \mathrm{C}$.

$$
\mathrm{q}_{\mathrm{t}}=\mathrm{k}_{\mathrm{p}} \mathrm{t}^{1 / 2}+\mathrm{C}
$$

Where $\mathrm{q}_{\mathrm{t}}$ is the amount of nitrate adsorbed in $\mathrm{mg} / \mathrm{g}$ of adsorbent at time $t, k_{P}$ is the intra-particle diffusion rate constant in $\left(\mathrm{mg} \mathrm{g}^{-1} \mathrm{~min}^{1 / 2}\right)$ and $\mathrm{t}$ is the agitation time in minutes. $\mathrm{C}$ is the intercept and its value gives an idea about the thickness of the boundary layer, i.e. the larger the intercept, the greater is the boundary layer effect (McKay et al., 1985). The adsorbate species are most probably transported from the bulk of the solution to the solid phase through intra-particle diffusion/transport process, which is often the rate limiting step in many adsorption processes, especially in a rapidly stirred batch reactor (Weber, 1972 and McKay, 1983), i.e., due to stirring there is a possibility of transport of nitrate species from the bulk into pores as well as adsorption at outer surface of HAp/Alg adsorbent nano-composite. The rate-limiting step may be either adsorption or intra-particle diffusion. So, the possibility of intra-particle diffusion was explored by using the intraparticle diffusion model (Equation 5). The correlation of the values of $\log$ (removal) and $\log$ (time) also resulted in linear relationships, which also indicate that the process of intraparticle diffusion is taking place in these adsorption systems. The divergence in the value of slope from 0.5 indicate the presence of intra-particle diffusion process as one of the rate limiting steps, besides many other processes controlling the rate of adsorption, all of which may be operating simultaneously (McKay et al., 1985 \& Weber and Morris, 1964). The results obtained are presented in the table (2) and graphically shown in the Figure (14). The values of $\mathrm{q}_{\mathrm{t}}$ were found to be linearly correlated with values of $t^{1 / 2}$. The rate constants $\left(K_{P}\right)$ for intra-particle diffusion of various initial nitrate concentrations were determined from the slope of respective plots. The (r-value) correlation coefficient $\left(\mathrm{R}^{2}\right)$ value is high, but not close to the unity, indicating that this model cannot be to apply. As well as intercept value indicate that the line was not passing through origin, i.e., there are some other process affect the adsorption. So, the intra-particle diffusion takes place along with other process that may affect the adsorption. It is evident from the curve that, the plot were straight lines but the y-intercept of the plot was nonzero (not passing through the origin), thus indicating that intra-particle diffusion is not the sole rate-limiting factor for the adsorption of nitrate onto HAp/Alg adsorbent nano-cmposite.

Finally, from the figures $\left(12,13\right.$ and 14) and table 2 , the $\mathrm{R}^{2}$ of the first-order kinetic model, pseudo second-order kinetic model and the intra-particle diffusion kinetic model for the HAp/Alg nano-composite were (0.907, 0.999 and 0.835), respectively. It is clear to see that the $\mathrm{R}^{2}$ value of the pseudo second-order kinetic model is much higher than those for the first-order kinetic and intra-particle diffusion kinetic models. Also, the amount of nitrate ion removed (q) that calculated from the pseudo second-order model (22.57) is nearly close to the practical adsorption capacity (22.5). Therefore, these results indicated that the pseudo second-order model represents is considered the best choice among the three kinetic models to describe the adsorption behavior of nitrate onto HAp/Alg nano-composite.

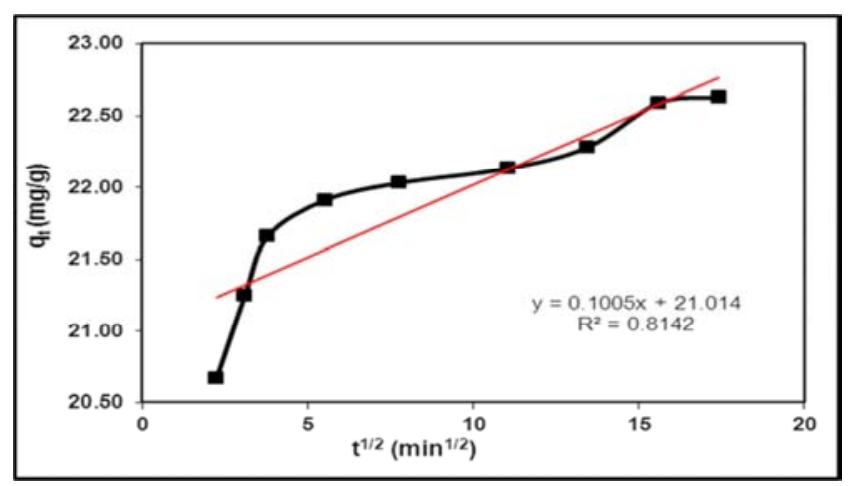

Figure 14. The intra-particle diffusion kinetic model of nitrate adsorption on HAp/Alg nano-composite at given conditions: contact time, 240min; $\mathrm{pH}, 3$; dosage, $2 \mathrm{~g}$ and $\mathrm{Ci}, 100$ at $20^{\circ} \mathrm{C}$. 
Table 2. Fixed values and regression coefficients of the adsorption kinetics of first-order, pseudo-second-order and intra-particle diffusion models for nitrate adsorption by HAp/Alg nano-composite.

\begin{tabular}{|c|c|c|c|c|c|c|c|c|}
\hline \multicolumn{3}{|c|}{ First-order-kinetic model } & \multicolumn{3}{|c|}{ Pseudo second-order kinetic model } & \multicolumn{3}{|c|}{ Intra-particle diffusion kinetic model } \\
\hline$k_{1}\left(\min ^{-1}\right)$ & $q_{1}(m g / g)$ & $\mathbf{R}^{2}$ & $k_{2}\left(g^{m g^{-1}} \min ^{-1}\right)$ & $\mathrm{q}_{2}(\mathrm{mg} / \mathrm{g})$ & $\mathbf{R}^{2}$ & $k_{p}\left(m g ~ g^{-1} \min ^{1 / 2}\right)$ & $\mathrm{C}(\mathrm{mg} / \mathrm{g})$ & $\mathbf{R}^{2}$ \\
\hline 0.4174 & 22.32 & 0.907 & 0.0387 & 22.57 & 0.9999 & 0.0983 & 20.999 & 0.8349 \\
\hline
\end{tabular}

\subsection{Adsorption Isotherms}

An equilibrium ratio of the quantity of adsorbed substance to mass unit of absorbent and its equilibrium state concentration in the liquid phase at constant temperature is called adsorption isotherm. It is one of the most important parameters to realize the mechanism of adsorption (Mohammad Hassan Shahmoradi et al., 2015). In order to determine the relationship between the amount of nitrate ions adsorbed on the adsorbent surface and the concentration of remaining metal ions in the aqueous phase, adsorption isotherm studies were performed. Among various binding models, the Langmuir and Freundlich isotherms have been frequently employed to describe the experimental data of adsorption isotherms.

The Langmuir isotherm is valid for monolayer adsorption onto a surface containing a finite number of identical sites. The model assumes uniform energies of adsorption onto the surface and no transmigration of adsorbate in the plane of surface (Soumya et al., 2015), i.e., the Langmuir adsorption isotherm is based on the monolayer sorption of metal ions on the homogeneous surface of the sorbent and is represented by the following equation (Morey et al., 2000);

$$
q_{e}=\frac{q_{\max } K_{L} C_{e}}{1+k_{L} C_{e}}
$$

The adsorption data were fitted to linearly transformed Langmuir isotherm, the linearized Langmuir equation, which is valid for monolayer sorption onto a surface with finite number of identical sites, is given by the following equation (Tahir, 2005);

$$
1 / \mathrm{q}_{\mathrm{e}}=\left(1 / \mathrm{q}_{\max }\right)+\left(1 / \mathrm{q}_{\max } \mathrm{K}_{\mathrm{L}} \mathrm{C}_{\mathrm{e}}\right)
$$

Where $\mathrm{q}_{\mathrm{e}}$ is the amount of nitrate adsorbed per unit mass of $\mathrm{HAp} / \mathrm{Alg}$ nano-comopsite adsorbent at equilibrium time $(\mathrm{mg} / \mathrm{g}), \mathrm{q}_{\max }$ is the maximum adsorption capacity which is the maximum required amount of the adsorbed component (nitrate) ion per unit mass of $\mathrm{HAp} / \mathrm{Alg}$ nano-comopsite adsorbent $(\mathrm{mg} / \mathrm{g})$ to form a complete monolayer on the actual surface of the adsorbent, $\mathrm{C}_{\mathrm{e}}$ is the equilibrium concentration of the adsorbate in solution $\left(\mathrm{mg} / \mathrm{L}\right.$ ) and $\mathrm{k}_{\mathrm{L}}$ (equilibrium adsorption constant) denotes the Langmuir constant $(\mathrm{L} / \mathrm{mg})$ that related to the energy of adsorption. The plotting $1 / \mathrm{q}_{\mathrm{e}} \mathrm{vs}$ $1 / \mathrm{C}_{\mathrm{e}}$ is shown in figure (15), where $\mathrm{q}_{\max }$ and $\mathrm{k}_{\mathrm{L}}$ can be obtained from the slope and intercept of the linear plot, respectively.

The other isotherm model that investigated in this work was Freundlich model. According to the Freundlich model, at equilibrium the amount of a substance adsorbed $\left(\mathrm{q}_{\mathrm{e}}\right)$ is related to the concentration of the solute $\mathrm{C}_{\mathrm{e}}$. Also, Freundlich equation can be derived by assuming that the free energy of adsorption decreases logarithmically as adsorption density increases.
The Freundlich isotherm model is considered to be appropriate for describing both multilayer sorption and sorption on heterogeneous surface. The Freundlich isotherm model can be expressed by the following equation (Ho et al., 2002):

$$
q_{e}=k_{F} C_{e}^{1 / n}
$$

Where $\mathrm{k}_{\mathrm{F}}$ and $\mathrm{n}$ are the Freundlich constants characteristic of the system which are indications of the adsorption capacity and adsorption intensity, respectively, of the system (Arica et al., 2003). Also, $\mathrm{C}_{\mathrm{e}}$ is the equilibrium concentration $(\mathrm{mg} / \mathrm{L})$ and $\mathrm{q}_{\mathrm{e}}$ is the amount adsorbed of nitrate at equilibrium time $(\mathrm{mg} / \mathrm{g})$. The linear form of the Freundlich isotherm model is obtained by taking logarithm from Equation (9):

$$
\ln \left(\mathrm{q}_{\mathrm{e}}\right)=\ln \left(\mathrm{k}_{\mathrm{F}}\right)+1 / \mathrm{n} \ln \left(\mathrm{C}_{\mathrm{e}}\right)
$$

By plotting $\ln \left(\mathrm{q}_{\mathrm{e}}\right) \mathrm{vs} \ln \left(\mathrm{C}_{\mathrm{e}}\right)$ as shown in figure $(16), \mathrm{k}_{\mathrm{F}}$ and $\mathrm{n}$ are obtained from the intercept and slope of the linear plot, respectively.

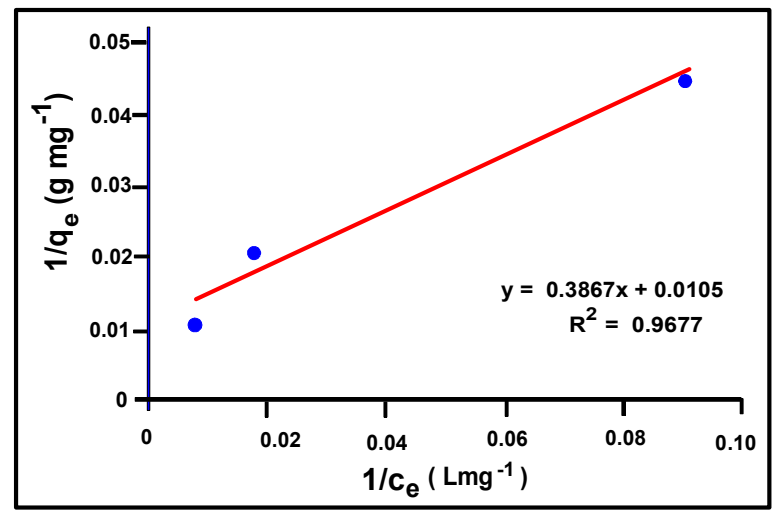

Figure 15. The Langmuir isotherm plot for nitrate adsorption onto HAp/Alg nano-composite at given conditions: contact time, 240min.; pH, 3; dosage, $2 \mathrm{~g}$ and $\mathrm{Ci}, 100$ at $20^{\circ} \mathrm{C}$.

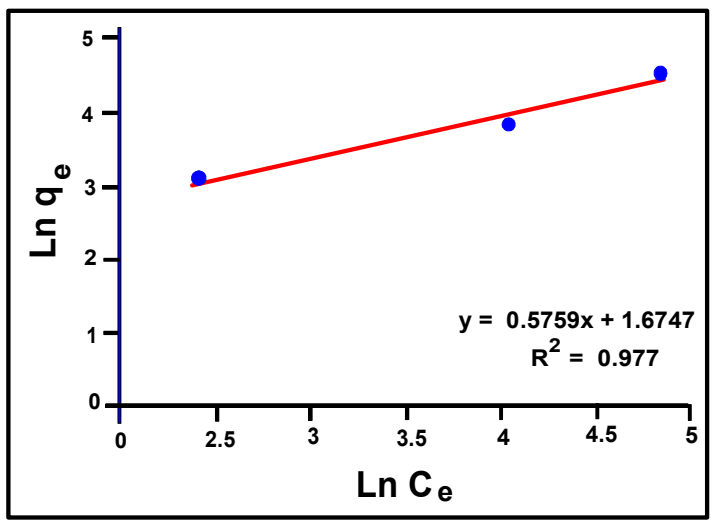

Figure 16. The Freundlich isotherm plot for nitrate adsorption onto HAp/Alg nano-composite at given conditions: contact time, 240min; $\mathrm{pH}, 3$; dosage, $2 \mathrm{~g}$ and $\mathrm{Ci}, 100$ at $20^{\circ} \mathrm{C}$. 
The studied Langmuir and Freundlich equilibrium isotherm (models) were carried out by using the experimental data obtained to describe the adsorption equilibrium of nitrate on HAp/Alg nano-composite in solution at constant temperature $20^{\circ} \mathrm{C}$. Figure (15) shows the graph of $1 / \mathrm{q}_{\mathrm{e}}$ vs $1 / \mathrm{C}_{\mathrm{e}}$ for Langmuir isotherm. Also, Figure (16) presents the linear curve fitting for the Freundlich model, using the same experimental data. The models' parameters are summarized in table (3).

Comparing the regression coefficient $\left(R^{2}\right)$ values, the Freundlich isotherm with $R^{2}(0.977)$ is nearly equal to that of the Langmuir isotherm $(0.968)$, while the practical adsorption capacity (22.5) is compatible with the maximum adsorption capacity (23.1) which calculated from Langmuir isotherm model, indicating that the adsorption obey the Langmuir model and made the Langmuir isotherm model was the most proper model to describe the equilibrium behavior of the adsorbent, i.e., the nano-composite showed better fit for Langmuir isotherm than Freundlich isotherm, suggesting the adsorption of nitrate onto HAp/Alg nano-composite is chemical process. Finally, the adsorption of nitrate onto HAp/Alg nano-composite was correlated well with Langmuir equation as compared to Freundlich equation.

Table 3. Langmuir and Freundlich isotherm models' parameters for of the adsorption process of nitrate by HAp/Alg nanocomposite.

\begin{tabular}{lllllllll}
\hline \multirow{2}{*}{ Nano-adsorbent } & \multirow{2}{*}{ Temp. (K) } & \multicolumn{2}{l}{ Freundlich isotherm } & \multicolumn{3}{l}{ Langmuir isotherm } \\
\cline { 3 - 10 } & & $\mathbf{1 / n}$ & $\mathbf{n}$ & $\mathbf{K}_{\mathbf{F}}(\mathbf{L} / \mathbf{m g})$ & $\mathbf{R}^{2}$ & $\mathbf{q}_{\mathbf{m}}(\mathbf{m g} / \mathbf{g})$ & $\mathbf{K}_{\mathbf{L}}(\mathbf{L} / \mathbf{m g})$ & $\mathbf{R}^{\mathbf{2}}$ \\
\hline nHAp/Alg & 293 & 0.588 & 1.7 & 0.576 & 0.977 & 23.1 & 0.39 & 0.968 \\
\hline
\end{tabular}

\subsection{Field Study}

The suitability of HAp/Alg nano-composite was tested with a field samples taken from the study area. About $2 \mathrm{~g}$ of adsorbent was added to $50 \mathrm{ml}$ of water sample and the contents were shaken with constant time $240 \mathrm{~min}$ at room temperature. As shown in table (4), the results indicated that the removal percentage reached about $99 \%$, which reveal that HAp/Alg adsorbent nano-composite can be effectively employed for removing the nitrate ion from groundwater.

Table 4. Field trial results of HAp/Alg nano-composite on groundwater samples at the study area.

\begin{tabular}{llll}
\hline Sample No. & Nitrate concentration before treatment & Nitrate concentration after treatment & Removal percentage (\%) \\
\hline 1 & 57.75 & 0.51 & 99.12 \\
2 & 65.13 & 0.6 & 99.07 \\
3 & 74.18 & 0.75 & 98.99 \\
\hline
\end{tabular}

\section{Conclusion}

This study demonstrated how the nHAp/Alg nanocomposite prepared and employed for the removal of nitrate ions from groundwater in a batch method, can be used as a more effective adsorbent in use. The alginate gel is prepared by diffusion method or gelation method when a calcium salt is added to a solution of sodium alginate in water. In gelation method, the crosslinking calcium ion diffuses from an outer reservoir into an alginate solution and the gel forms by a chemical reaction, the calcium displaces the sodium from the alginate, holds the long alginate molecules together and a gel is resulted. No heat is required and the gel does not melt when heated. The HAp/Alg nano-composite adsorbent was synthesized by in situ hybridization. The FT-IR spectroscopy results indicate that there is a chemical interaction takes place between the inorganic and polymeric constituents in the composite. The chemical interaction is assumed to be mediated by the chemical bonding between $\mathrm{Ca}^{2+}$ and the carboxyl groups in alginate. Maximum equilibrium capacity is $99 \%$ of nitrate removal was obtained using the HAp/Alg nano-composite after $240 \mathrm{~min}$; at $\mathrm{pH}, 3$; adsorbent dosage, $2 \mathrm{~g}$, initial concentration, $100 \mathrm{mg} / 1$ and temperature $20^{\circ} \mathrm{C}$. The kinetics of nitrate adsorption onto the nHAp/Alg nanocomposite revealed that nitrate ions adsorbed satisfactorily, according to the pseudo second-order equation. Fitting of the kinetic data of the adsorbent nHAp/Alg to pseudo secondorder indicates that the concentration of both adsorbate and adsorbent are involved in the rate determining step of the adsorption process. Also, the Langmuir isotherm model fitted the equilibrium data better than the Freundlich isotherm, which demonstrated homogeneous surface with monolayer of adsorbate. The process can be employed for the removal of nitrate to meet the permissible limit of nitrate for human drinking water in both surface and groundwater. Finally, the beads type nHAp-alginate composite adsorbent was found to be promising for nitrate ions removal from aqueous solutions.

\section{References}

[1] Akçelik, O.; Tosun, A. and Ergun, M., 2008. Biosorption of copper (ii) from aqueous solution by Saccharomyces cerevisiae, $4^{\text {th }}$ European Bioremediation Conference, Greece.

[2] ALDAR, CH2M Hill, Spain, 2011. Study of environmental and social impact assessment framework (ESIAF) of Assiut \& Sohag governorates. Executive Summary, Egypt, 82p.

[3] Annadurai, G. and Krishnan M. R. V., 1996. Adsorption of basic dye using chitin. Indian J Environ Protec. 16 (6): 444-449. 
[4] Arica, M. Y.; Arpa, C.; Ergene, A.; Bayramoglu, G. and Genc, O., 2003. Ca-alginate as a support for $\mathrm{Pb}(\mathrm{II})$ and $\mathrm{Zn}(\mathrm{II})$ biosorption with immobilized Phanerochaete chrysosporium, Carbohydr. Polym., 52: 167-174.

[5] Cantor, K. P., 1997. Drinking water and cancer. Cancer Causes Control, 8: 292-308.

[6] Census estimation, 2015. Estimation of Central Agency for Public Mobilization and Statistics, 2015 (in Arabic)

[7] Do gan, M. and Alkan, M., 2003. Adsorption kinetics of methyl violet onto perlite. Chemosphere, 50 (4), 517-528.

[8] Dorsche, M. M.; Scragg, R. K. R.; McMichael, A. J.; Baghurst, P. A. and Duer, K. F., 1984. Congenital malformation and maternal drinking water supplying rural South Australia: a case study. Am. J. Epidemiol., 119: 473-486.

[9] Elmoubarki, R.; Mahjoubi, F. Z.; Tounsadi, H.; Moustadraf, J.; Abdennouri, M.; Zouhri, A.; ElAlbani, A. and Barka, N., 2015. Adsorption of textile dyes on raw and decanted Moroccan clays: Kinetics, Equilibrium and Thermodynamics. Water Resources and Industry, 9: 16-29.

[10] Fahimeh Googerdchian; Ahmad Moheb and Rahmatollah Emadi, 2012. Lead sorption properties of nanohydroxyapatite-alginate composite adsorbents. Chemical Eng. J., 200, 202: 471-479.

[11] Ganjali, M. R.; Babaei, L. H.; Norouzi, P.; Pourjavid, M. R.; Badiei, A.; Saberyan, K.; Maragheh, M. G.; Salavati-Niasari, M. and Ziarani, G. M., 2005. Novel method for the fast separation and purification of molybdenum (VI) from fission products of uranium with aminofunctionalized mesoporous molecular sieves (AMMS) modified by dicyclohexyl-18crown-6 and S-N tetradentate Schiff's base. Analytical Letters, 38 (11): 1813-1821.

[12] Grant, G. T.; Morris, E. R.; Rees, D. A.; Smith, P. J. and Thom, D., 1973. Biological interaction between polysaccharides and di-valent cations. The egg-box model. FEBS Lett, 32: 195-198.

[13] Hekmatzadeh, A. A.; Karimi-Jashani, A.; Talebbeydokhti, N. and Kløve, B., 2012. Modeling of nitrate removal for ion exchange resin in batch and fixed bed experiments, J. Desalination, 284: 22-31.

[14] Ho, Y. S. and McKay, G., 1999. Pseudo-second order model for sorption processes, Process Biochem. 34: 451-465.

[15] Ho, Y.; Porter, J. and McKay, G., 2002. Equilibrium isotherm studies for the sorption of divalent metal ions onto peat: copper, nickel and lead single component systems. Water, Air \& Soil Pollution, 141 (1-4): 1-33.

[16] Honghe, Z., 1997. Interaction mechanism in sol-gel transition of alginate solutions by addition of divalent cations. Carbohydr. Res., 302: 97-101.

[17] Ingleton, I. and Simmons, P., 1996. Factors affecting silver biosorption by an industrial strain of Saccharomyces cerevisiae. J. Chem. Technol. Biotechnol., 65: 21-28.

[18] Islam, M. and Patel, R., 2011. Physicochemical characterization and adsorption behavior of $\mathrm{Ca} / \mathrm{Al}$ chloride hydrotalcite - like compound towards removal of nitrate. J. Hazard. Mater. 190: 659-668.

[19] Jae-HeeAhn; Kwang-Ho Choo and Hak-Soon Park, 2008. Reverse osmosis membrane treatment of acidic etchant wastewater: Effect of neutralization and polyelectrolyte coating on nitrate removal, J. Membrane Sci., 310: 296-302.

[20] Kapoor, A. and Viraraghavan, T., 1997. Nitrate removal from drinking water-review. J. Environ. Eng., 123: $371-380$.

[21] Kar, S.; Khan, D. K. and Santra, S. C., 2002. Groundwater nitrate concentration and its impact on human health: a review. Every man's Sci., 37: 35-40.

[22] Kesseru, P.; Kiss, I.; Bihari, Z. and Polyak, B., 2002. Investigation of the denitrification activity of immobilized Pseudomonas butanovora cells in the presence of different organic substrates. Water Res., 36: 1565-1571.

[23] Kikuchi, M.; Itoh, S.; Ichinose, S.; Shinomiya, K. and Tanaka, J., 2001. Self-organization mechanism in a bone-like hydroxyapatite / collagen nano-composite synthesized in vitro and its biological reaction in vivo. Biomaterials, 22: 17051711.

[24] Komath, M. and Varma, H. K., 2003. Development of a fully injectable calcium phosphate cement for orthopedic and dental applications. Bull. Mater. Sci., 26 (4): 415-422.

[25] Mahamudur Islam; Prakash Chandra Mishra and Rajkishore Patel, 2010. Physicochemical characterization of hydroxyapatite and its application towards removal of nitrate from water. J. Environ. Manage., 91: 1883-1891.

[26] Malberg, J. W.; Savage, E. P. and Osteryoung, J., 1978. Nitrate in drinking water and the early onset of hypertension. Environ. Pollut., 15: 155-161.

[27] McKay, G., 1983. The adsorption of dye stuff from aqueous solution using activated carbon: analytical solution for batch adsorption based on external mass transfer and pore diffusion. Chem. Eng. J., 27:187.

[28] McKay, G.; Otterburn, M. S. and Aja, J. A., 1985. Fullter's earth and fired clay as adsorbents for dyes stuffs. Water Air Soil Pollut. 24: 307.

[29] Mishra, P. C. and Patel, R. K., 2009. Use of agricultural waste for the removal of nitrate-nitrogen from aqueous medium, J. Environ. Manage., 90: 519-522.

[30] Mohammad Hassan Shahmoradi; Behnoush Amin Zade; Ali Torabian and Mahdi Seyed Salehi, 2015. Removal of nitrate from groundwater using activated carbon prepared from rice husk and sludge of paper industry wastewater treatment. ARPN J. Eng. and Applied Sci., 10 (17): 7856-7863.

[31] Morey, M. S.; O’Brien, S.; Schwarz, S. and Stucky, G. D., 2000. Hydrothermal and post-synthesis surface modification of cubic, MCM-48 and ultra large pore SBA-15 mesoporous silica with titanium. Chemi. of Materi. J., 12 (4): 898-911.

[32] Moussavi, G. and Khosravi, R., 2011. The removal of cationic dyes from aqueous solutions by adsorption onto Pistachio Hull Waste. Chemical Eng. Res. and Design J., 89: 2182-2189.

[33] Nayak, D. and Lahiri, S., 2006. Biosorption of toxic, heavy, no-carrier-added radionuclides by calcium alginate beads, $\mathrm{J}$. Radioanal. Nucl. Chem., 267: 59-65.

[34] Prakasa Rao, E. V. S. and Puttanna, K., 2000. Nitrates, agriculture and environment. Current Sci., 79: 1163-1168.

[35] Ravikrishna, R.; Ren, M. and Valsaraj, K. T., 2006. Lowtemperature synthesis of porous hydroxyapatite scaffolds using polyaphron templates, J. Sol-Gel Sci. Technol., 38: 203-210. 
[36] Ruiz-Hitzky, E., 2003. Functionalizing inorganic solids: towards organic-inorganic nanostructured materials for intelligent and bio-inspired systems. The Chemical Record, 88-100.

[37] Ryker, S. J. and Jones, J. L., 1995. Nitrate concentrations in groundwater of the central Columbia plateau. U.S. Geological Survey Fact Sheet, FS-061-97.

[38] Sachin N. Milmile; Jayshri V. Pande; Shilpi Karmakar; Amit Bansiwal; Tapan Chakrabarti and Rajesh B. Biniwale, 2011. Equilibrium isotherm and kinetic modeling of the adsorption of nitrates by anion exchange Indion NSSR resin, Desalination, 276: 38-44.

[39] Sefner, W., 1995. Natural water contents and endemic goitera review. Zentralb. Hyg. Umweltmed., 196: 381-398.

[40] Selvam, P.; Bhatia, S. K. and Sonwane, C. G., 2001. Recent advances in processing and characterization of periodic mesoporous MCM-41 silicate molecular sieves. Indus. \& Eng. Chemi. Res. J., 40 (15): 3237-3261.

[41] Sheridan, M. H.; Shea, L. D.; Peters, M. C. and Mooney, D. J., 2000. Bioabsorbable polymer scaffolds for tissue engineering capable of sustained growth factor delivery. J. Control Release, 64: 91-102.

[42] Soumya, G. N.; Manickavasagam, M.; Santhanam, P.; Dinesh Kumar, S. and Prabhavathi, P., 2015. Removal of phosphate and nitrate from aqueous solution using seagrass Cymodocea rotundata beads. African J. Biotechno. 14 (16): 1393-1400.

[43] Sudipta Chatterjee; Dae S. Leeb; Min W. Leec and Seung H. Woo., 2009. Nitrate removal from aqueous solutions by crosslinked chitosan beads conditioned with sodium bisulfate, J. Hazard. Mater., 166: 508-513.

[44] Super, M.; Heese, H.; Machenzie, D.; Dempster, W. S.; Duplers, J. and Ferreina, J. J., 1981. An epidemiological study of well water nitrates in a group of southwest African/Namibian infants. Water Res., 15: 1265-1270.

[45] Sutherland, I. W., 1991. Alginates. In: Byron D, editor. Biomaterials: novel materials from biological sources. New York: Stockton Press, 309-331.

[46] Suriyaraj, S. P. and R. Selvakumar, 2016. Advances in nanomaterial based approaches for enhanced fluoride and nitrate removal from contaminated water. RSC Adv., 6: 10565-10583.

[47] Tahir, H., 2005. Comparative trace metal contents in sediments and liquid waste from tanneries and their removal of chromium using Zeolite-5A. Electronic J. Environ., Agricultural and Food Chemistry, EJEAFCHE 4 (4): 10211032.
[48] Teng, S.; Shi, J.; Peng, B. and Chen, L., 2006. The effect of alginate addition on the structure and morphology of hydroxyapatite gelatin nano-composites. Compos. Sci. Technol., 66:1532-1538.

[49] Van Maanen, J. M. S.; Van Dijk, A.; Mulder, K.; De Baets, M. H.; Menheere, P. C. A.; Van Der Heide, D.; Mertens, P. L. J. M. and Kleinjans, J. C. S., 1994. Consumption of drinking water with high nitrate levels causes hypertrophy of the thyroid. Toxicol. Lett., 72: 365-374.

[50] Vimonses, V.; Lei, S.; Jin, B.; Chow, C. W. K. and Saint, C., 2009. Adsorption of Congo Red by three Australian kaolin's. Applied Clay Sci. J., 43: 465-472.

[51] Wahab, M. A.; Jellali, S. and Jedidi, N., 2010. Effect of temperature and $\mathrm{pH}$ on the biosorption of ammonium onto Posidonia oceanica fibers: Equilibrium, and kinetic modeling studies. Bioresour. Technol., 101: 8606-8615.

[52] Wang, Z.; Zhang, Q.; Konno, M. and Saito, S., 1993. Sol-gel transition of alginate solution by the addition of various divalent cations: ${ }^{13} \mathrm{C}-\mathrm{NMR}$ spectroscopic study. Biopolymers, 33:703-711.

[53] Wang, Li.; Yue, Li. and Chunzhong, Li., 2009. In situ processing and properties of nanostructured hydroxyapatite / alginate composite. J. Nanopart. Res., 11: 691-699.

[54] Weber, Jr. W. J., 1972. Physico-chemical processes for water quality control. New York: Wiley Interscience, 27: (Chapter 5) 207-234.

[55] Weber, W. J. and Morris, J. C., 1964. In: Eckenfelder, W. W, editor. Advances in water pollution research. Oxford: Pergamom Press.

[56] WHO, 2011. Guidelines for drinking-water quality. Recommendations. $4^{\text {th }}$ ed. Geneva, World Health Organization. ISBN 9789241548151.

[57] Yadav, A. K.; Kaushik, C. P.; Haritash, A. K.; Kansal, A. and Rani, N., 2006. Defluoridation of groundwater using brick powder as an adsorbent. J. Hazard. Mater. 128: 289-293.

[58] Yuh-Shan Ho., 2005. Comment on "Nitrate removal from aqueous solution by adsorption onto various materials" by N. O” ztu“rk, T. E. Bektas, J. Hazard. Mater., B, 118: 253-254.

[59] Zhang, J.; Wang, Q. and Wang, A., 2010. In situ generation of sodium alginate/hydroxyapatite nano-composite beads as drug-controlled release matrices. Acta Biomaterial, 6: 445454. 